\title{
Pictorial materials used in the polychrome decorations of the façade of the palace of King Pedro I (The Royal Alcazar of Seville, Spain)
}

\author{
O. López-Cruz®, A. García-Bueno, V.J. Medina-Flórez, A. Sánchez-Navas, N. Velilla \\ Universidad de Granada (Granada, España) \\ \olimpia@ugr.es
}

Received 1 July 2014

Accepted 30 December 2014

Available on line 13 M arch 2015

\begin{abstract}
This research has been conducted on the architectural decoration of the façade of the Palace of King Pedro I (The Royal Alcazar of Seville, Spain). The stratigraphic study of pictorial layers has revealed numerous interventions made on the polychrome decorations that have been related to those referenced in historical documents. Mineralogical and compositional studies of the natural and synthetic pigments and their alteration have provided an independent chronology for the polychrome decorations. Finally, this study has revealed the importance of colour of the decorative elements over the history of the palace.
\end{abstract}

KEYWORDS: Polychromy; Pigment; Binder; Technics; Characterization

Citation/Citar como: López-Cruz, O.; García-Bueno, A.; Medina-Flórez, V.J.; Sánchez-Navas, A.; Velilla N. (2015) Pictorial materials used in the polychrome decorations of the façade of the palace of King Pedro I (The Royal Alcazar of Seville, Spain). Mater. Construcc. 65 [318], e054 http://dx.doi.org/10.3989/mc.2015.04314.

RESUMEN: Materiales utilizados en la policromía de la fachada de Pedro I (Real Alcázar de Sevilla, España). El estudio de la fachada del palacio de Pedro I ha puesto de manifiesto la existencia de un gran número de policromías realizadas con una amplia variedad de pigmentos de diferentes cronologías. Mediante diversas técnicas analíticas han sido diferenciadas y caracterizadas química y mineralógicamente. El estudio estratigráfico detallado de las diferentes policromías ha permitido relacionarlas con las sucesivas intervenciones documentadas, comprobando así la gran importancia que el color ha tenido en todas las épocas o momentos históricos del Palacio.

PALABRAS CLAVE: Policromía; Pigmento; Aglutinante; Técnicas; Caracterización

Copyright: (c) 2015 CSIC. This is an open-access article distributed under the terms of the Creative Commons Attribution-Non Commercial (by-nc) Spain 3.0 License.

\section{INTRODUCTION}

The Palace of King Pedro I was built between 1356 and 1366 within the precinct of the Royal Alcazar of Seville (Spain) and is one of the most outstanding monuments of medieval architecture in Spain. Over its history, the entire Alcazar has undergone constant remodelling and rehabilitation as a consequence of being the oldest palace in use by the Spanish monarchy, first as the residence of the Moorish heads of state and after the reconquest of Seville to the present, as an official royal residence.
The façade of this palace, the most representative element of the precinct, is divided into three main sections, the central or portal and the two lateral ones, constructed of different materials, all originally polychromed. Notable among these is the monumental eave made of polychromed wood (Figure 1).

Under the arrocabe (ornate frieze) in the central section are two bands of decorated wall tiles in blue and white that separate the eave from the lower part of the main section. This lower zone is constructed in carved stone with intricate ornamentation of 


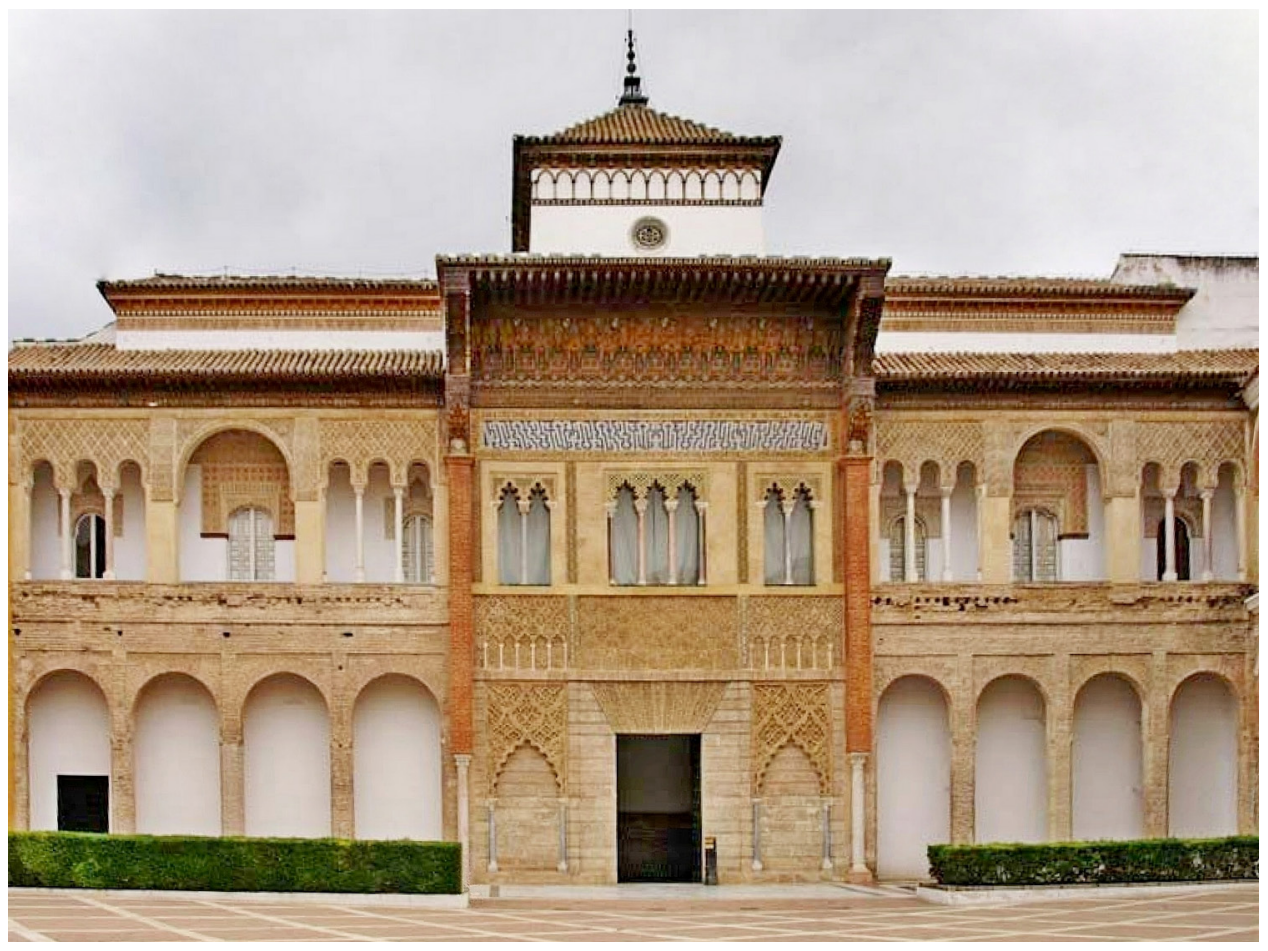

Figure 1. Current state of the façade of the Palace of King Pedro I after restoration.

atauriques (stylized plant motifs) that must have been originally polychromed.

In the lateral sections of the portal, under the eaves, yeserías (decorative gypsum plasterwork) bears the same chromatic finishes as used on the wood of the façade. Made in the times of the Catholic Monarchs, these finishes follow the Nazarí style. Under them stand the original arches of the palace, which were closed probably at the end of the $15^{\text {th }}$ century and reopened in 1937.

This study was focused on the study of the polychrome decorations and made by the work team Wall Coating and Architectural Finishes, within the research group of the Regional Government of Andalusia Laboratory of City Archaeology and Architecture (HUM-104), under the research project of excellence of the Regional Government of Andalusia Colour in the Polychromed Façade of the Palace of Pedro I in the Royal Alcazar of Seville (HUM-02829). Given the great quantity of pictorial strata found in the polychrome decoration of the facade, our aim was to quantify and identify the different actions taken in retouching the polychromes and thereby establish the chromatic evolution of the different decorative elements.

\section{METHODOLOGY}

For this study of the polychrome elements, a specific sampling method was used consisting of collecting the samples in the predetermined areas after dividing the decorated surface of each main section of the façade into three areas, i.e. left, right, and central. Within each area, 14 horizontal levels were differentiated, which in turn were divided in three zones. These levels were structured taking as a reference the ornamental elements and the different colours found in these.

From the overall façade, a total of 242 samples were taken, 94 from the central section, and 74 from each of the two lateral sections. This high number of samples was necessary to establish the complete register of the different polychroming of the various ornamental elements and their changes in colour.

The scientific-technical research undertaken is fundamental for knowledge of the materials, the execution processes, and alterations. In our case, this was focused on identifying the interventions made over the years on the basis of characterizing and comparing the samples in order to establish the correspondence between the different polychrome levels.

The analysis techniques used were:

- Stereoscopic microscopy for the observation of the total sample that provided an initial and major source of information on the materials and the succession of existing strata.

- Preparation of samples as polished sections and polished thin sections that enabled the examination of the succession of pictorial layers and the subsequent identification of materials 
by optical microscopy (transmitted-light and reflected-light microscopy).

- Polarizing optical microscopy for the determination of the number, type and colour of the preparatory, base and pictorial layers, as well as for the textural study and characterization of their inorganic constituents. Carl Zeiss-Jena Jenalab and Olympus BX-60 microscopes equipped with a micro-photographic system DP-20 were used to obtain numerous optical images with transmitted and reflected light and viewed with crossed and parallel nicols.

- Scanning electron microscopy (SEM) to obtain back-scattered electron (BSE) and secondary electron (SE) images and energy dispersive X-ray (EDX) analyses of the pictorial layers, by using Leo Gemini 1530 and Leo 1430VP (VP-SEM) scanning electron microscopes, coupled with EDX microanalysis Inca 350. Micro-analyses were carried out with both instruments operated at $500 \mathrm{pA}$ filament current, $20 \mathrm{keV}$ beam energy, and $10 \mathrm{eV} / \mathrm{ch}$ for spectral resolution. $\mathrm{X}$-ray maps were acquired with the last machine operated at $1 \mathrm{nA}$ filament current and $20 \mathrm{eV} / \mathrm{ch}$ resolution.

- XRD diagrams of some pigments were recorded using a PANalytical X'Pert Pro diffractometer ( $\mathrm{Cu}-\mathrm{K} \alpha$ radiation, $45 \mathrm{kV}, 40 \mathrm{~mA}$ ) equipped with an X'Celerator solid-state lineal detector. The diffraction patterns were made by a continuous scan between $4-70^{\circ} 2 \theta$, with a $0.01^{\circ} 2 \theta$ step size and $20 \mathrm{sec}$ time step. The data were processed using the XPowder ${ }^{\circledR}$ program in order to determine the mineral composition (1).

- Single-point Raman microanalyses were performed on polished sections for the identification of pigments of the pictorial layers. Spectra were collected using a JASCO NRS-5100 confocal microRaman spectrometer equipped with an 1800 line $\mathrm{mm}^{-1}$ grating monochromator, Peltier cooled CCD Detector and Olympus objective lenses. The excitation source was a 532 solidstate laser operating at $0.7 \mathrm{~mW}$ output power. An objective lens (N.A. $=0.9$ ) of magnification $100 \times$ was used. Raman spectra, with $2 \mathrm{~cm}^{-1}$ of spectral resolution, were recorded in the ranges $100-1200 \mathrm{~cm}^{-1}$ using integration times of $10 \mathrm{~s}$ per accumulation over 2 accumulations. The spectra were calibrated with respect to the $520 \mathrm{~cm}^{-1}$ line of a silicon plate. Identification of pigments was done by using RRUFF database and in a lesser extend VISART database, as well available publications (2-4).

- Gas chromatography (GC) for the characterization of the lipid binders, mainly linseed oils. Untreated samples were prepared by methylation of fatty acids using the Meth Prep II reagent and toluene. A Perkin Elmer Clarus 500 gas chromatographer equipped with a flame ionization detector was used in this study. Injections were made in the splitless mode and the HP-5 colunm (5\% phenyl methyl silicone, Hewlett-Packard, USA) was used with a temperature program from 120 to $300^{\circ} \mathrm{C}(5)$. Proteinaceous media were analyzed by high pressure liquid chromatography (HPLC) by using a Konik instrument, and with a UV-VIS detector at $200 \mathrm{~nm}$. The samples were subjected to acid hydrolysis $(6 \mathrm{~N} \mathrm{HCl}, 24 \mathrm{hr})$ and to derivatization with phenylisothiocyanate prior to the separation with a ODS Spherisorb column according to Halpine (6).

- Infrared (IR) absorption spectrometry for the analysis of base layers and protective varnish coatings. Spectra were recorded with $\mathrm{KBr}$ slices on Nicolet-20SXB FTIR spectrometer $\left(4000-370 \mathrm{~cm}^{-1}\right)$ and using the UATR (Universal Attenuated Total Reflectance) technique.

\section{POLYCHROME MATERIALS}

Any polychrome finish usually contains the following superimposed strata: preparatory layer, base layer, pigments and, in many cases, gold gild. In the samples studied, in addition to the identification of different pictorial materials comprising the façade of the Palace of King Pedro I, the strata making up the same polychromed area were recognized in order to determine the number of polychrome coats present in each sample studied.

Once assigned to polychrome groups, the strata were classified primarily according to the chronology provided by the pigment present in each stratum, which was described according to its chemical and mineralogical characteristics. The first polychrome type corresponded to the oldest materials, called historical. The second type was associated with the intermediate levels, in which synthetic azurite was identified, this pigment being discovered at the beginning of the $17^{\text {th }}$ century. Finally, the third group contained pigments and agglutinants of the most recent period, their manufacture being related to technological advances that led to the Industrial Revolution from the end of the 18th to the end of the 19th century, and were applied in later restoration.

\subsection{Materials of the preparatory and base layers}

The preparatory layer associated with the original polychrome was distinguished by several characteristics: 1) It invariably appeared over the original support and often was severely deteriorated, with only scant remains; 2) it had a characteristic dull brownish colour; 3 ) its composition was normally mostly earth materials (phyllosilicates and quartz) and a small portion of gypsum.

By contrast, the rest of the preparation layers presented lighter colours than the original and 
were essentially composed of gypsum, with a small quantity of phyllosilicates.

The preparation layers were present, under stereoscopic microscope, as masses of earth colours, poorly compacted. Under optical microscope small, regular crystals were appreciable. In BSE (backscattered electrons) images of the SEM, these crystals appeared with dark-grey colours due to their low mean atomic number. EDX (energy-dispersive $\mathrm{X}$-ray) analysis indicated peaks of $\mathrm{S}$ and Ca corresponding to the calcium sulphate (gypsum). Also, other elements were identified, these being the phyllosilicate components often accompanying this gypsum in these types of layers ( $\mathrm{Si}, \mathrm{Al}, \mathrm{K}, \mathrm{Na}$, etc.).

The base strata of the deepest pigments appeared highly degraded, not only for their age but also because they generally contained higher amounts of gypsum than of white lead or calcite. Meanwhile, the most recent strata, with a great quantity of these latter materials, were more compact and better defined, and under the stereoscopic microscope appeared as well-defined layers of white colour. Under the optical microscope, crystals of variable size and morphology were visible. In BSE images with SEM, these appeared with intermediate grey colours due to their higher mean atomic number with respect to the older layers. The element analysis revealed the presence of $\mathrm{Ca}, \mathrm{S}$, and $\mathrm{Pb}$ and, in some cases (especially the most recent strata), $\mathrm{Ba}$. This chemical composition corresponded to materials of calcium carbonate, calcium sulphate, white lead, and barium sulphate; this latter was found only very occasionally.

For recent restorations, two strata appeared as a base, presenting distinctive characteristics with respect to the previous ones, as both contained high percentages of lead. The deepest was an extremely compact layer composed exclusively of white lead. This differs from preceding and subsequent painting, which in addition to this pigment contained variable quantities of gypsum or calcite.

With respect to the last intervention, corresponding to the polychromy visible at present, the base layer bore a large quantity of white lead, but calcite was added in proportions that sometimes made it the majority mineral. Some samples also contained variable quantities of barite and occasionally a small proportion of gypsum.

\subsection{Pigments identified in the pictorial layers}

White lead (lead hidroxycarbonate and lead carbonate). These have been used since antiquity, produced by diverse procedures over time. Hydrocerussite $\left(\mathrm{Pb}_{3}\left(\mathrm{CO}_{3}\right)_{2}(\mathrm{OH})_{2}\right)$ together with cerussite $\left(\mathrm{PbCO}_{3}\right)$ were the most abundant pigment in the samples studied and were used both for base strata as well in pictorial finishes (Figures 2, 3 and 4). In the pictorial layers, it had the same characteristics as described above for the base layers. It formed very compact and well-defined layers that under the optical microscope were found to be composed of brilliant rounded grains of very small size $(1 \mu \mathrm{m})$. Under transmitted-light microscopy, the white lead presents strong opacity. In BSE images, these layers appeared with bright grey colours due to the high mean atomic number of this pigment. In the Raman spectra both hydrocerussite and cerussite are characterized by a very strong peak near $1050 \mathrm{~cm}^{-1}$, but the corresponding to cerussite appears slightly displaced to a higher wave number that of hydrocerussite (Figure 3).

Calcite. This is a form of calcium carbonate $\left(\mathrm{CaCO}_{3}\right)$ that has been used since antiquity, especially in preparatory layers and to a lesser degree as a pigment (7). It can be natural or artificial in origin. Its natural varieties include chalk, which is a white, soft and porous rock, composed of an accumulation of the remains of marine microorganisms. In the samples in which it appeared, especially in the deep strata, it contained fossils debris, confirming that it is natural.

Baryte (barium sulphate, $\mathrm{BaSO}_{4}$ ). This is a very stable white pigment but with moderate covering power. It is used primarily as a base for preparations and as a component or adulterant for other white pigments (8). In the Alcazar, this mineral appeared especially together with arsenate of copper greens and to give body to black in the modern polychroming of the central section of the façade. Bearn (9) pointed out that when barium sulphate is used together with a pigment that is not a white colour, such as green, it should not be considered an adulterant as it heightens the shine and gives a product of better optical properties at a low cost. In the case of samples studied, it appeared in both cases, together with white lead and calcite in the preparation layers, and together with green pigments of arsenic and copper for greater shine (Figures 5, 6 and 7).

Organic black. This pigment is produced by the combustion of several organic substances. Though not very consistent, it is extremely permanent and has a great power of coloration. This use of this colour has been confirmed in Roman painting (10). All the black colours found in the samples studied were formed by organic pigments. Normally, organic black does not show its characteristics under the optical microscope or SEM. Only a massive and homogeneous aspect was visible with the presence of craquelure due to the retraction of the abundant oils and resins that these pigments contained. The layers that formed often lost their continuity at the cost of the plastic behaviour of the material (Figure 4). 


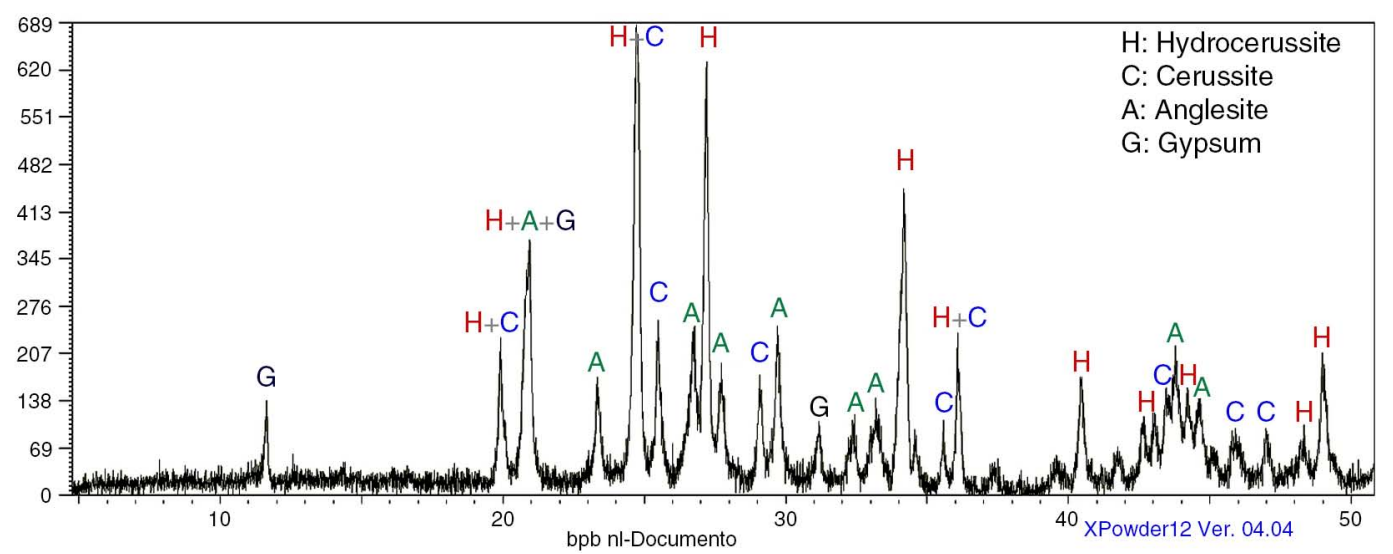

FIGURE 2. XRD pattern corresponding to white lead composed of hydrocerussite and cerussite, with a lesser amount of anglesite. The presence of gypsum is due to contamination by the base layer.

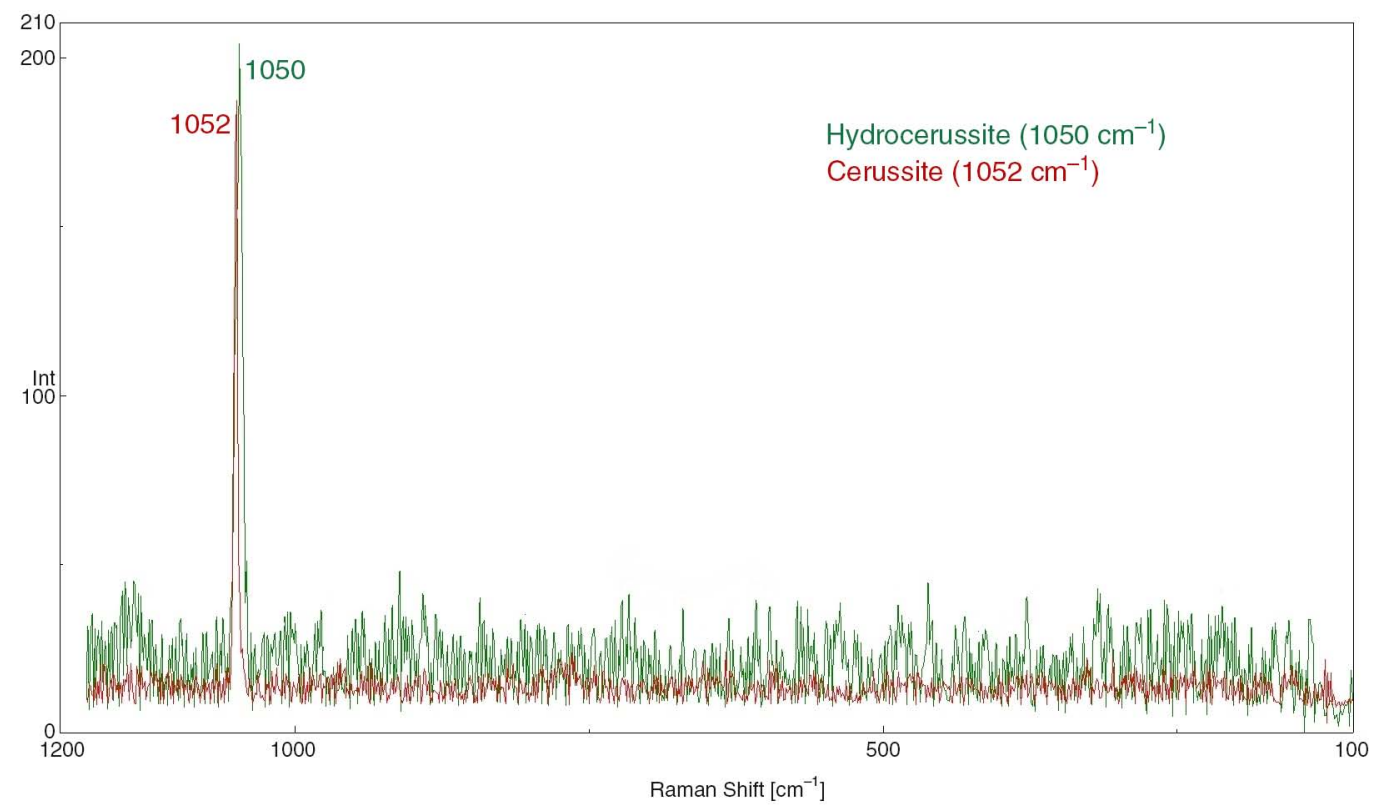

FIGURE 3. Raman spectra of white lead pigment corresponding to hydrocerussite and cerussite.

In addition to the organic agglutinants, they usually contained pigments that gave them body and acted as a drying agent and that varied according to the location of the sample. Thus, in the lateral areas of the façade, it was found mixed with red lead or vermillion, especially in the modern polychroming, while in the main section the accompanying pigment was barite. In deeper strata of the three main sections of the façade, this pigment was mixed with other drying pigments, i.e. mainly white lead, azurite, and red lead.

The Raman spectrum of this pigment is characterized by bands at 1570,1360 , and $1250 \mathrm{~cm}^{-1}$.

Lead(II) oxide or litharge. This is a lead monoxide $(\mathrm{PbO})$ which was used traditionally as a drying agent in oil painting, although it was also used as a pigment to a lesser degree. It has been made synthetically since antiquity by heating molten lead in the presence of air at $300^{\circ} \mathrm{C}$.

This pigment, like white lead, was found in the samples as a base or pictorial stratum and both in the electronic images as well as in the microanalysis of SEM-EDX it presented characteristics that were practically identical with white lead and therefore were impossible to differentiate. Also, the size of the crystals detected by optical microscopy was very similar in the two pigments. However, the two can be distinguished optically by the clear yellow colour of the lead oxide (Figure 8).

Lead-tin yellow (lead-tin oxide). This is produced by the fusion of lead and tin oxides in a crucible at temperatures of $800{ }^{\circ} \mathrm{C}$ (11). The most common 


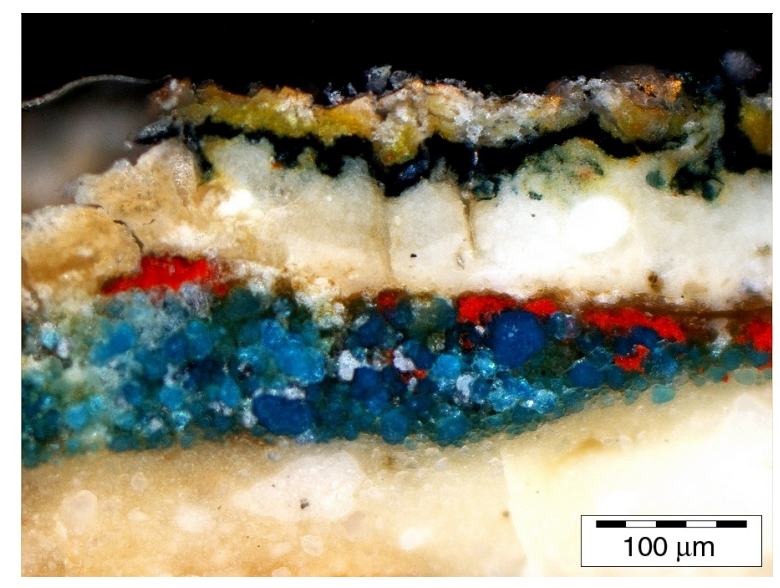

FIGURE 4. Microphotograph using reflected light (LR) under crossed polars (XP) of a stratigraphic section composed by synthetic azurite and red lead (central area) located between two layers of white lead. Upper sequence is as follow: a layer made of organic black, a gold base with chrome yellow, and a final gold layer.

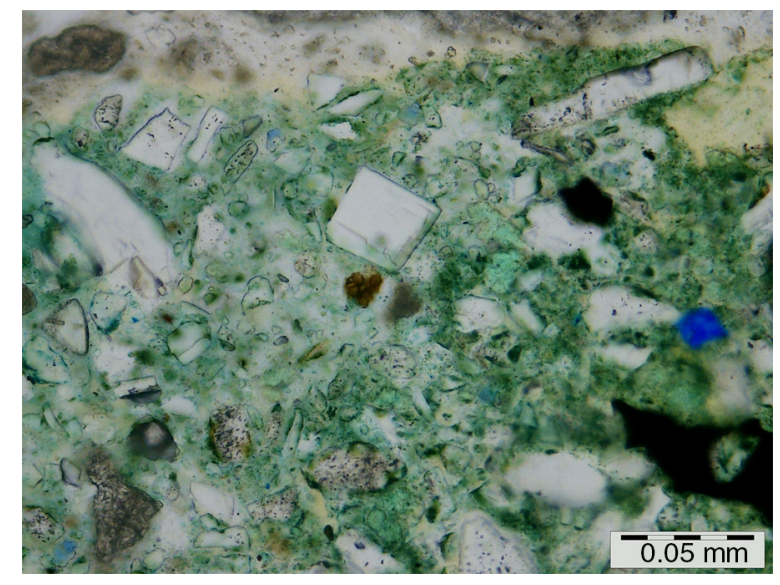

FIgURE 5. Transmitted polarized light image of a detail of a layer formed by copper arsenites and crystals of barium sulphate (colourless) that heighten the shine of the green pigment. compound is an oxide of the formula $\mathrm{Pb}_{2} \mathrm{SnO}_{4}$, although another is also known, this containing a small proportion of $\mathrm{Si}$, replacing $\mathrm{Sn}$. The origin of this pigment is unknown but it was used in Egypt and Mesopotamia.

In the façade, crystals of this pigment appeared intimately mixed with those of malachite, which was visible only in the study of the microsamples under the optical microscope. In fact, the lead-tin yellow can be concealed by malachite and only the crystals of larger size could be characterized well for their particular yellow colour (Figure 9). The use of EDX microanalysis enabled a confident determination on the basis of the characteristic association of the spectral lines of $\mathrm{Pb}$ and $\mathrm{Sn}$. In the BSE images appeared crystals of lead-tin yellow, of high atomic number, with levels of greys close to white, and with irregular sizes and shapes. Also, this pigment has been detected in the Raman spectra by the presence of strong bands in the low wave number region, especially those corresponding to 194 and $128 \mathrm{~cm}^{-1}$.

Red lead (lead oxide, $\mathrm{Pb}_{3} \mathrm{O}_{4}$ ). This is produced by calcination of white lead at about $450{ }^{\circ} \mathrm{C}$. The product is a dense material, fine grained, with a high covering power (12).

This pigment is very significant in the polychroming of the façade, as it constituted the base stratum of the original polychromy over supports of wood and stone. It formed part of the deepest preserved layers (Figure 10). In most cases, it was manifested as disperse nodules of larger or smaller size with varying tonalities from intense red to orangish shades; although in some cases, it was conserved with a more continuous structure and with tonalities, under the optical microscope, shined brightly. Crystals of lead oxide have rounded morphologies and sizes ranging from 1 to $3 \mu \mathrm{m}$.

In the intermediate and upper levels of polychromed wood, it almost disappeared and, when

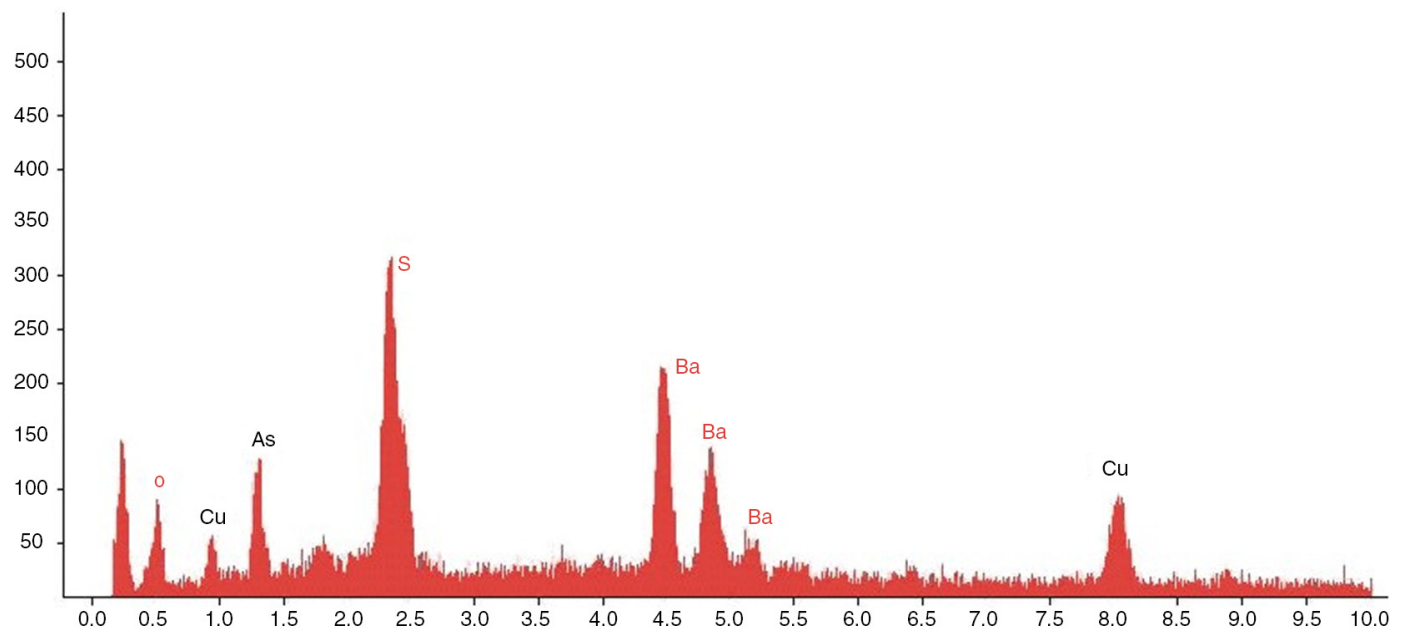

FIGURE 6. EDX spectrum of the copper arsenite green pigment and barium sulphate pigment of the pictorial layer shown in Figure 5. 


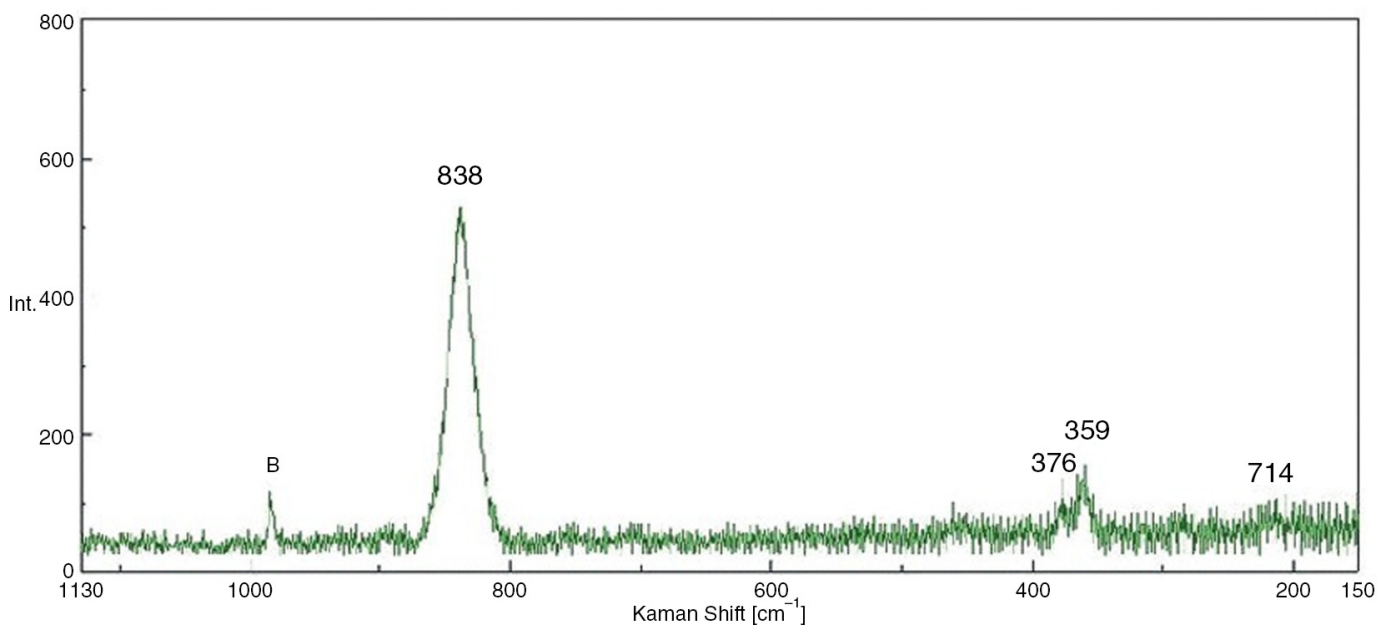

FIGURE 7. Raman spectrum corresponding to copper arsenite green pigment with minor barite of Figure 5.

found, usually went together with vermilion. In gypsum plasterworks (yeserías), it is main pigment used for the diverse decorative elements in the colour red.

Cinnabar/Vermilion (mercury sulphide, $\mathrm{HgS}$ ). This pigment can be made in a natural form by grinding the mineral cinnabar or it can be produced artificially by synthesis (vermilion). The two pigments, natural and synthetic, have the same chemical formula, and therefore cannot be distinguished by element analysis with SEM-EDX.

In the samples studied, both the natural product as well as the synthetic one could be appreciated (Figures 11 and 12). Nevertheless, it might be deduced that the natural pigment must have been used profusely in the Royal Alcazar, as the edifice

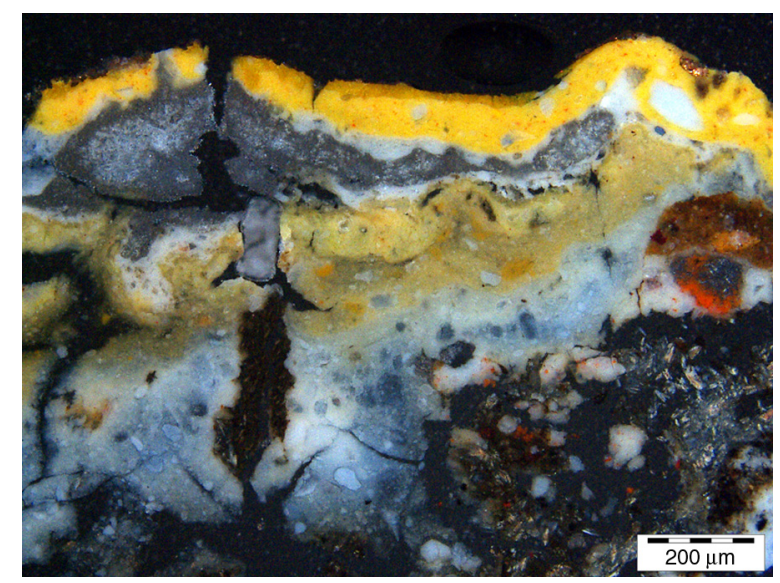

FigURE 8. Yellow layers used as the base layer for the gold or with the function of simulating a yellow tone analogous to gold. From the centre to the top: a yellow layer of litharge and iron oxyhydroxides, a layer of white lead and calcite, other layer of chrome yellow with minor white lead, and a gold layer. In lower part of the image, a preparation layer (bottom) is followed by a base layer of white lead (reflected light, LR and crossed polars, XP). was built not far the mines of Almadén, the largest producers of cinnabar in the world.

However, with respect to the use of the two types of pigment in these samples, in agreement with the differences indicated, cinnabar seems to be found in the deepest layers, considered as the original ones, and vermilion-type pigment in the upper layers. Both appeared under the stereoscopic microscope as layers of bright red, very compact and relatively well preserved. They were distinguished in some cases under the optical microscope. Thus in the case of natural pigment (cinnabar), crystals of more uniform size appeared $(2-3 \mu \mathrm{m})$, normally associated with some quartz grains from the original rock. On the contrary, the pigment vermilion, under the optical microscope, presented a colour that was sometimes orangish, the crystals were smaller, regular, and predominantly between 1 and $2 \mu \mathrm{m}$ in size.

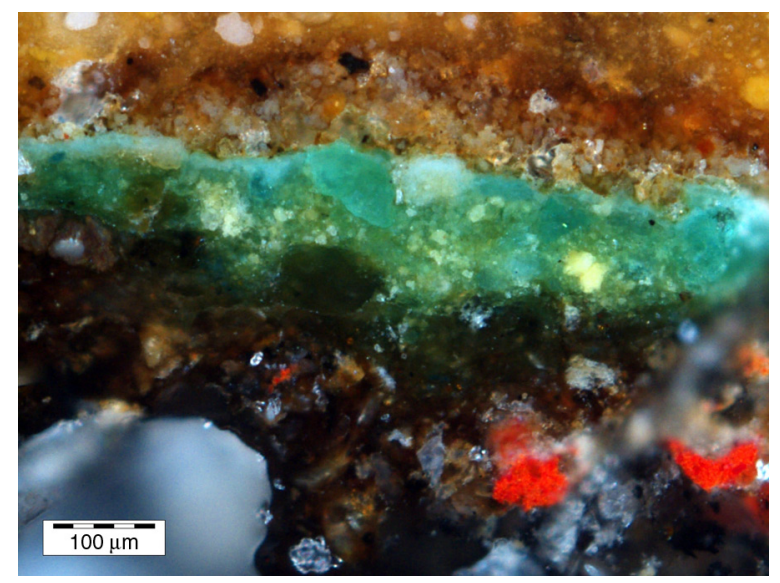

FiguRE 9. Microphotograph of a green layer of the original polychrome constituted by malachite and lead-tin yellow pigments. At the lower part of the image, scant remains of the deepest layers formed by red lead, corresponding to the original polychrome, can be appreciated (RL and XP). 


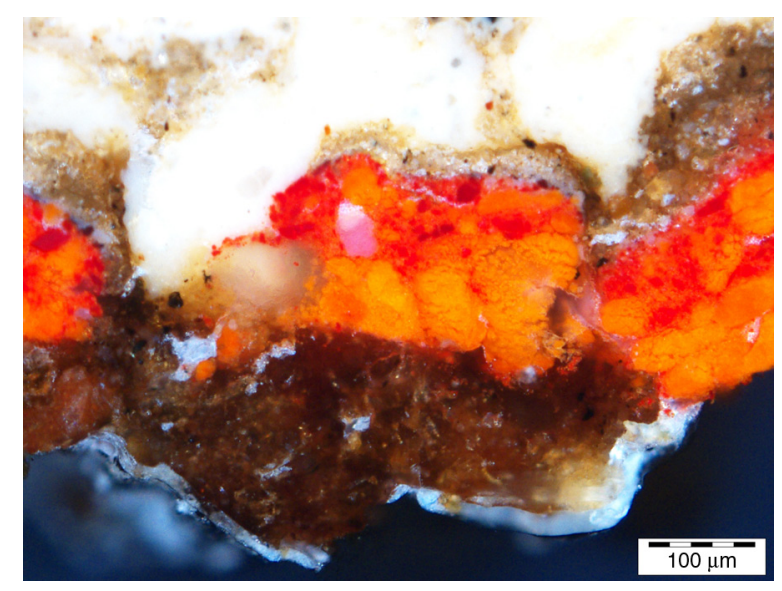

FIGURE 10. Optical image under reflected light and crossed polars of the original polychrome. Here the sequence comprises a lower preparation layer with phyllosilicates and gypsum, a layer of red lead and an upper layer of white lead.

The main difference with respect to natural pigment is that the synthetic one did not contain impurities, in particular, quartz.

In the BSE images, the brightness of these layers, because their high mean atomic number (71a.n.) was very high. EDX spectra of mercury sulphide presented the superimposition of the spectral lines corresponding to the two constituent elements $\mathrm{Hg}$ and $\mathrm{S}$. In the Raman spectra, both cinnabar and vermilion have as the only significant reference an intense spectral band at $252 \mathrm{~cm}^{-1}$.

Iron oxide red. This is a natural pigment that comes from clayey earth in red tones, which contains the mineral hematite. This pigment can be natural or artificial, but the chemical composition is always based on iron oxide $\left(\mathrm{Fe}_{2} \mathrm{O}_{3}\right)$.

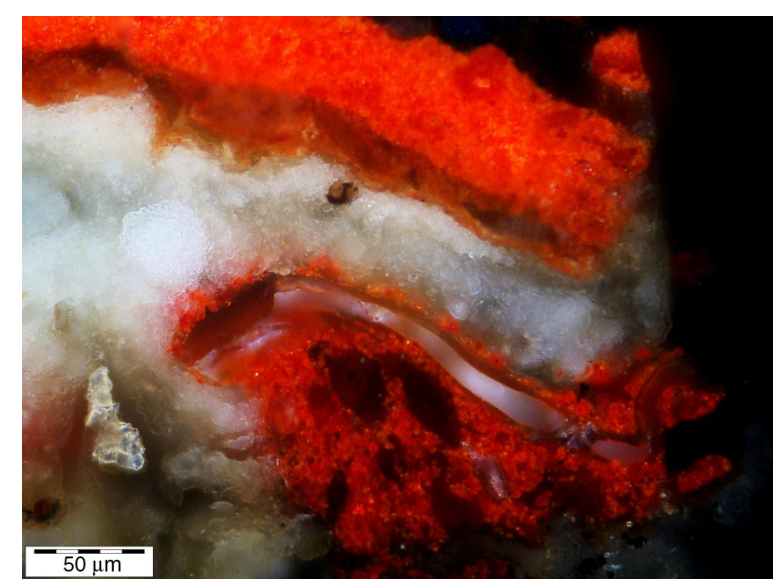

FIGURE 11. Red pictorial layers composed by cinnabar (lower one) and vermilion (upper one) with an intermediate layer of white lead. A thin stratum of iron oxides red appears below the vermilion layer (RL and XP).
In the samples studied, this pigment presented a brownish-red colour in quite continuous layers of coloration, almost always situated above strata of vermilion in the intermediate polychrome layers. Under the optical microscope, its texture is heterogeneous for being composed of a mixture of clayey materials that also included quartz, with hematite iron oxides.

In the reflected-light images with cross polarisers, these layers show a reddish-brown tone as opposed to the red of the cinnabar or vermilion strata (Figure 12). However, in the examinations under reflected light and a single polarizer, there was a strong contrast with the red layers that accompanied it due to its low reflectance of light. In the BSE image revealed little brightness due to the low mean atomic number of the different mineral components. In the EDX spectra, the peaks $\mathrm{Si}, \mathrm{Al}, \mathrm{K}, \mathrm{Mg}$ predominated, corresponding to the silicate minerals (clay and quartz) together with iron corresponding to iron oxides.

These oxides are mainly characterized in the Raman spectrum by a prominent band located at $401 \mathrm{~cm}^{-1}$.

Azurite. This is a mineral pigment that is found in the oxidation zone of primary copper deposits. It is composed of basic copper carbonate, $\mathrm{Cu}_{3}\left(\mathrm{CO}_{3}\right)_{2}(\mathrm{OH})_{2}$. The pigment of natural azurite was used by the ancient Egyptians and continued to be used throughout antiquity. In Europe, however, it did not begin to be used frequently until the $12^{\text {th }}$ century, when this mineral was discovered in silver mines of Saxony and large deposits were found near Lyon. Its artificial production dates to the $17^{\text {th }}$ century and was later substituted in great part by Prussian blue, which was discovered in the $18^{\text {th }}$ century (13).

This was a very common pigment in the samples studied, both in its natural variant, which was found at the deepest levels, and in it synthetic form. Under the stereoscopic microscope, the natural and the artificial pigment formed well defined, relatively thick, strata with a granular texture. The natural azurite crystals observed by optical microscopy presented irregular shapes, very angular and of notable size with a highly variable granulometry ranging from 10 to $50 \mu \mathrm{m}$ (Figure 13). The strata of synthetic azurite were characterized by the massive presence of spherulites with diameters of 10 to $15 \mu \mathrm{m}$, which were composed of an aggregate of small needle crystals in a fibrous-radial array (Figures 14 and 15). In the BSE images of SEM, the natural or synthetic azurite appear with intermediate grey to dark levels corresponding to an intermediate mean atomic number (19.4). The EDX spectra were very simple as they presented significant peaks corresponding only to copper. 

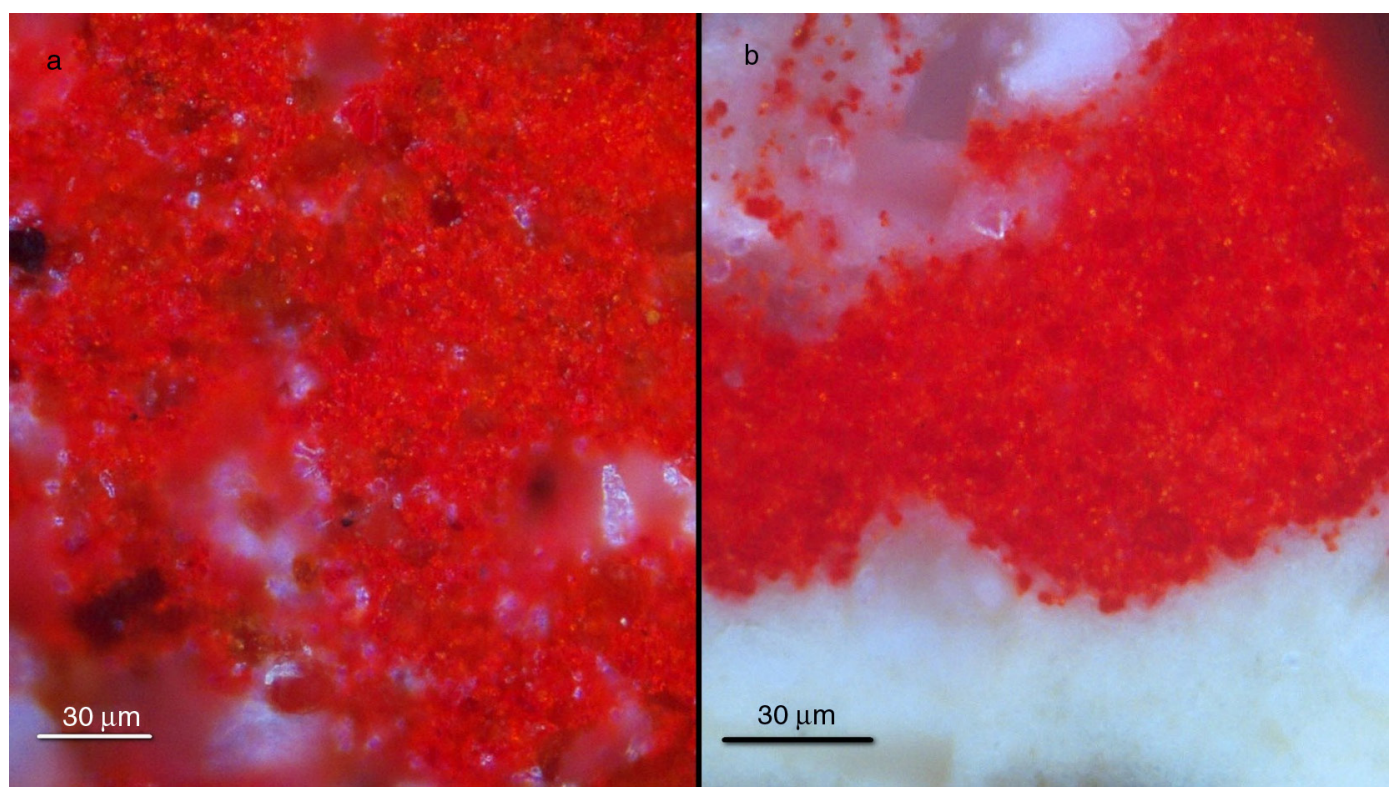

FIGURE 12. Details of the mercury sulphide red pigments (RL and XP). On the left side, an original polychrome containing the natural pigment cinnabar and minor impurities of quartz. On the right side, the synthetic pigment (vermilion) is formed by smaller crystals with homogeneous sizes and is free of impurities.

In the Raman spectrum, it can be distinguished with a characteristic band at $400 \mathrm{~cm}^{-1}$ and an array of minor bands at low wave numbers.

Ultramarine blue. This (sodium and calcium sulfo-aluminosilicate) was first synthesised in 1828 (14). Its chemical composition can be expressed as $\mathrm{Na}_{10} \mathrm{Si}_{6} \mathrm{Al}_{6} \mathrm{O}_{24} \mathrm{~S}_{2}$, which is similar, although not identical to the mineral lazurite. The product obtained by synthesis presents greater purity than that of mineral origin (15).

In samples studied, the synthetic variety invariably appeared and was never found in the deep

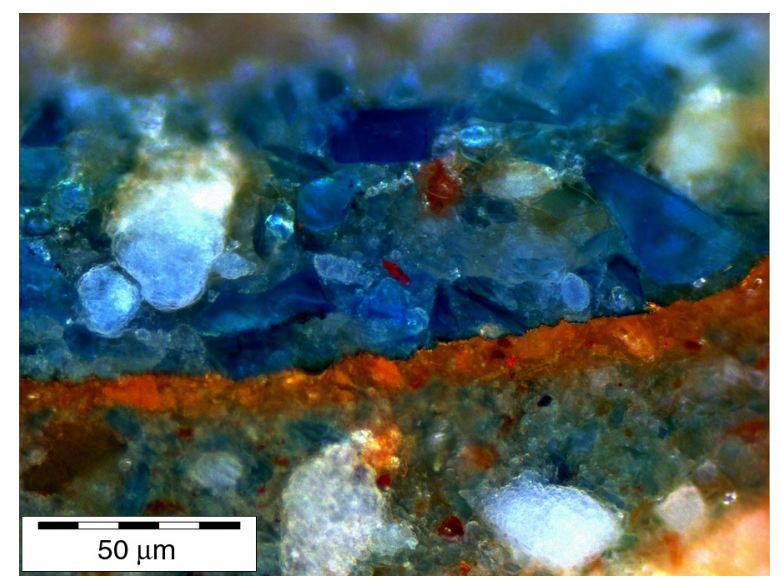

FIGURE 13. Detail of a layer of natural azurite with white lead (upper) on a gold layer with its preparation base. An older stratum also composed of natural azurite with white lead appears in the lower part (RL and XP). polychrome layers. In the most recent polychromies, it formed very characteristic strata under the microscope, where the intense blue colour of this pigment highlighted the white lead matrix that it accompanied in the pictorial layer (Figure 14). The proportion of ultramarine crystals with respect to the matrix was relatively small. These crystals were predominantly equidimensional, although they also appeared with irregular shapes. They had uneven granulometry and their size rarely surpassed $10 \mu \mathrm{m}$. Its isotropic character, apart from the colour, was the foremost optical property for its identification by optical microscopy.

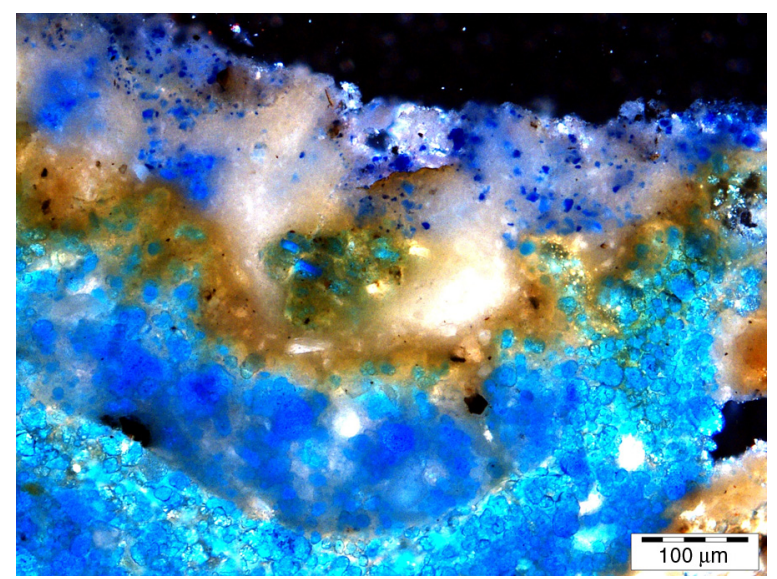

FIGURE 14. Pictorial sequence composed of two blue strata of synthetic azurite followed by a layer made up of a mixture of oil and resins, a layer of white lead, and a final layer of intense blue colour of ultramarine crystals mixed with white lead (RL and XP). 


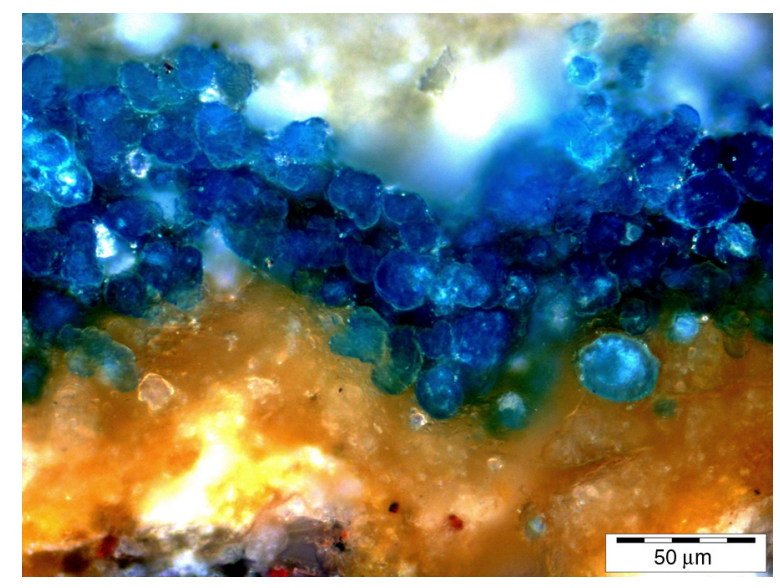

FIGURE 15. Detail of a yellow layer rich in oils and varnishes (lower part of the image) used to refresh the paints. At the centre, stratum of synthetic azurite grains WITH spherulitic morphology (RL and XP).

The BSE images of the strata showed great contrast between the ultramarine blue that appeared practically black due to its very low mean atomic number (less than 12) and the brilliance of the white lead (averaging approximately 67). The EDX spectra were very characteristic with the sequence of lines Na-Al-Si-S-(K-Ca) that clearly defines its composition.

The spectrum Raman is also very typical with an intense central band at $544 \mathrm{~cm}^{-1}$, a medium band at $544 \mathrm{~cm}^{-1}$, and two low-intensity bands at approximately 985 and $260 \mathrm{~cm}^{-1}$.

Malachite. This is probably the oldest green pigment known, clearly more abundant than azurite. Composed of basic copper carbonate $\mathrm{Cu}_{2}\left(\mathrm{CO}_{3}\right)$ $(\mathrm{OH})_{2}$, it often appears as botryodal masses with an internal fibrous structure. The material is prepared simply by grinding and, like azurite, the colour intensity decreases sharply with the decrease of grain size. Also, it is manufactured artificially although it was not identified as such in the polychroming of the façade, where little was identified and only in the deep layers (Figure 9). It was present in the floral ornament of the channels of the central section, where it was intimately mixed with lead-tin yellow.

The Raman spectrum of malachite contains numerous bands with a main band at $432 \mathrm{~cm}^{-1}$. The position of strong bands in the low wave number region of the spectrum below $400 \mathrm{~cm}^{-1}$ enables azurite to be distinguished.

Emerald green (copper acetate-arsenite). With the chemical formula $3 \mathrm{Cu}\left(\mathrm{AsO}_{2}\right)_{2} \cdot \mathrm{Cu}\left(\mathrm{CH}_{3} \mathrm{COO}\right)_{2}$, this was first manufactured in 1814 in Schweinfurt (Germany) (15). This serves to situate the pigment, as with other synthetic colours, chronologically in the stratum where it appears. It soon became a very popular pigment, presenting a darker and more brilliant colour than its predecessor Scheele's green and was a higher-quality pigment.

Emerald green was detected in many samples in the façade. Under the stereoscopic microscope, it formed layers of intense green that were sometimes very deteriorated. This pigment presented a variable tonality depending on the degree of alteration or of its impregnation of oil, but when it was not degraded, it had a highly saturated and brilliant green hue (Figure 16).

Both by optical microscope as well as by BSE with FESEM, the images showed crystallization into spherulite forms, composed of very regular needle crystals with a radiating fibrous texture. The size or the spherulites normally ranged from 5 to $10 \mu \mathrm{m}$, but some reach $30 \mu \mathrm{m}$. In these BSE images, pictorial layers composed of emerald green appeared as grey layers in accord with the intermediate mean atomic number of this pigment (approx. 24). The EDX spectrum of this pigment showed the characteristic lines of As and $\mathrm{Cu}$.

The Raman spectrum is very characteristic with a profusion of intense bands in the lower part of the spectrum, below $400 \mathrm{~cm}^{-1}$.

Copper arsenite green. This green could be associated with Scheele's green, discovered in 1775 by the Swedish chemist C.W. Scheele, who used arsenic and copper to produce this green. This is an inorganic pigment of variable composition and heterogeneous, as reflected by the fact that a dozen compounds have been described under this name that correspond mainly to copper arsenites, although they also include some arsenate (16). In the studied samples it appears only in the most recent polychroming of 1898.

The most characteristic aspect of this pigment was its invariable association with barite in all the studied samples in which it appeared. Barite was

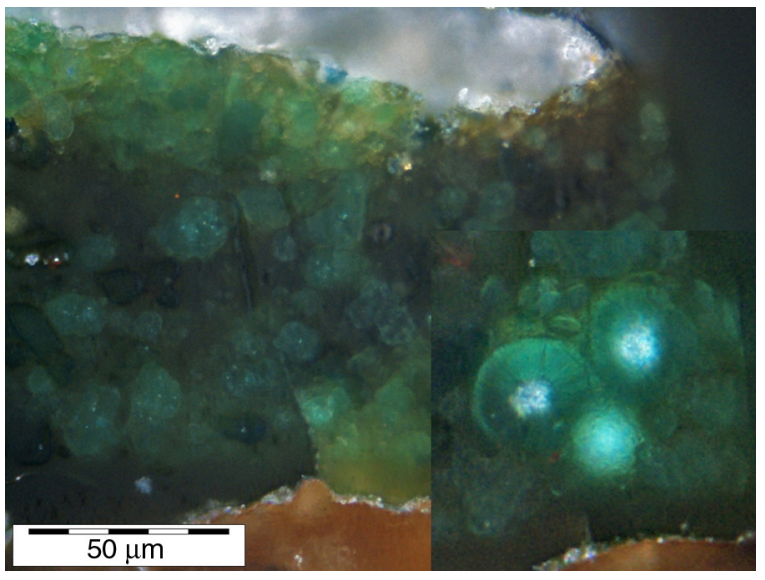

FIgure 16. Pictorial layer constituted by emerald green pigment which forms spherulites with an internal radiating fibrous texture (detail on the right-hand side; RL and XP). 
found forming irregular grains or, in some cases, euhedral crystals, and with variable size that can exceed $50 \mu \mathrm{m}$, and thus can be well identified optically. The green pigment did not show crystallinity under the optical microscope and formed a matrix of intense green colour among grains of barite, which, given their transparency and refraction index, heightened the brightness of the resulting pigment. The analytical EDX data showed only the presence of the spectral lines of $\mathrm{As}$ and $\mathrm{Cu}$, in addition to those associated with the presence of barite (Figures 5 and 6).

\subsection{Gilding}

Gold is a very common element in the polychromy of the façade, and in the samples studied it appeared from the deepest strata to the most superficial ones (Figures 8 and 17, and Table 1). In the most superficial strata, where the gold layer was better conserved, the design could be traced by more or less continuous and brilliant lines. In the EDX microanalysis, only the spectral lines of the gold appeared, indicative of its purity, although at times it could be found forming alloys with silver and copper, the latter being detected in minor proportions, both in the earlier and later layers.

\subsection{Agglutinants of the preparatory, base and pictorial layers}

The analytical results showed a quite homogeneous use of the agglutinants over time. Thus, the deepest (original) polychromed layers, i.e. preparatory and base, were agglutinated with animal glue which in some cases contained traces of linseed oil and colophony resin, probably from the migration of the superimposed layers (e.g. Figure 17, and Table 1). Afterwards, animal glue continued to be used to agglutinate the preparatory strata of the three later polychrome strata.
With respect to the base layers of white lead or those constituted by this pigment, appearing in intermediate or superficial polychrome layers, in all the cases were agglutinated with linseed oil, with traces of colophony resin appearing in many cases.

In the pictorial layers, even greater homogeneity was found, since all the samples analysed belonging to the different levels were agglutinated with linseed oil and in many cases also had traces of colophony resin (Figure 17, and Table 1). The only exception found, though important, was a sample belonging to the mocarabes (honeycomb stalactite ornamentation) that presented egg as the agglutinant in the original layer of red lead, indicating that it was made with a tempera technique (Figure 18, and Table 2). This confirms the documentary references (17) that cite this technique in the original polychroming.

\subsection{Yellow layers used as the gold base or as the pictorial layer}

These bright yellow layers were used in interventions most recent of 1848 and were made up of a mixture of oil and resins plus pigments such as ochres or litharge (Figure 8), which were used as the base layer for the gold. All these strata in the microanalysis by SEM-EDX presented a great variety of elements such as $\mathrm{Pb}, \mathrm{Fe}, \mathrm{Ca}$, and $\mathrm{S}$. The relative proportions of these chemical elements enabled the distinction of one layer from another, although this does not usually strongly influence their final tonality. All of them had the function of simulating a yellow tone analogous to gold, but using a cheaper product. In some cases, these layers were used so that, on applying the gold layer, the possible gaps would go unnoticed. In other cases, the pigment was not even gilded. The deep layers were composed of white lead and iron oxides, while the last presented chrome yellow (Lead(II) chromate, $\mathrm{PbCrO}_{4}$ ) as the pigment providing the

TABLE 1. Colour, pigments and agglutinants of the preparatory, base and pictorial layers of the polychrome decorations from the left corbel (mensula) of the façade (Figure 17)

\begin{tabular}{llll}
\hline No. layer & Colour & \multicolumn{1}{c}{ Pigments } & \multicolumn{1}{c}{ Agglutinants } \\
\hline 1 & Brown & Phyllosilicates, gypsum & Animal glue, linseed oil, traces of colophony resin \\
2 & White/red & White lead, red lead & Linseed oil \\
3 & Brown & Iron oxides & Linseed oil \\
4 & Golden & Gold & \\
5 & Brown & Phyllosilicates, gypsum & Animal glue \\
6 & Brown & Iron oxides & Linseed oil, colophony resin \\
7 & Golden & Gold & \\
8 & White & White lead, calcite & Linseed oil, colophony resin \\
9 & Yellow & Chrome yellow, white lead & Linseed oil, colophony resin \\
10 & Golden & Gold & \\
\hline
\end{tabular}




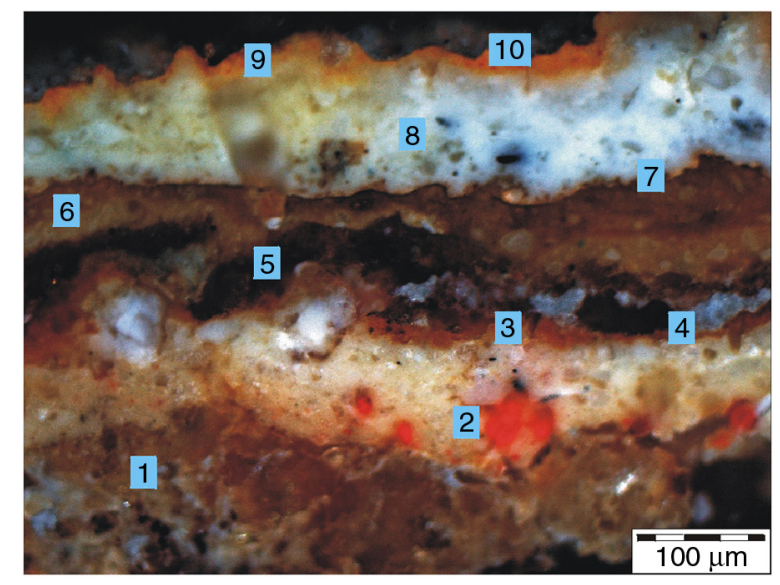

FIGURE 17. Reflected light image (crossed polars) corresponding to three gilded polychromes. The observed layers correspond to: 1) deeper preparatory layer composed by phyllosilicates and gypsum, which were agglutinated with animal glue (see Table 1); 2) base layer of white and red lead; 3 ) gold base formed by iron oxides and linseed oil; 4) gold layer; 5) preparatory layer agglutinated with animal glue; 6) gold base composed mainly by iron oxides agglutinated with linseed oil and colophony resin (Table 1); 7 ) gold layer; 8) base layer constituted by white lead and calcite agglutinated with linseed oil and colophony resin; 9) yellow layer used as the gold base made

up of a mixture of oil and resins plus pigments such as chrome yellow and white lead; 10) gold layer.

colour of this layer. The SEM-EDX microanalyses of these layers indicated that in all cases there was a majority proportion of white lead.

There were other layers of yellow colour, less intense, that corresponded to applications of oils and varnishes used mainly to refresh the paints. These layers were darker under the optical microscope and SEM for being an organic material of low molecular weight.

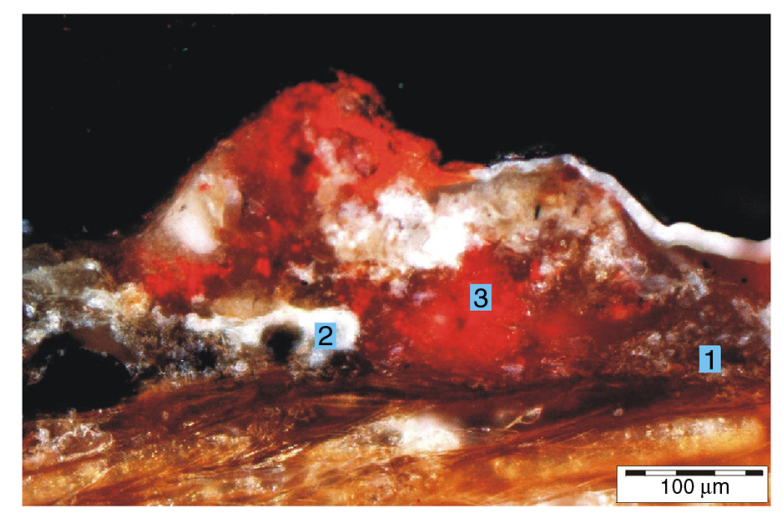

FIGURE 18. Reflected light image (crossed polars) of an original polychrome (deepest levels) from the honeycomb work or stalactite work (mocárabes) of the façade. It is composed by three layers: 1) preparatory layer formed by phyllosilicates and gypsum; 2) original base layer formed by white lead, quartz and calcite agglutinated with animal glue and linseed oils; 2) pictorial layer with lead red pigment and egg as the agglutinant (tempera technique; see also Table 2).
Other differentiating traits of these strata include the size as well as the shape that was so peculiar of the pigment particles. Thus, the iron oxides and litharge appeared as large nodules in the whitelead matrix, while in the strata containing chrome yellow, the pigment in question was constituted by small, dispersed crystals that offer a very saturated orangish yellow colour in the white-lead layer (Figure 15).

The BSE images showed practically no differences, as all the compounds had a high mean atomic number and their differences were minor, so that the coefficient of electron backscattering was quite similar and therefore so was the brightness of the image.

\section{CONCLUSIONS}

In general, it is deduced that the Palace of King Pedro I has been carefully maintained, as it has benefited from being a palace under constant care, having remained under royal use until the present. As a result, there have been numerous pictorial interventions of the façade of the palace and 9 polychromy levels, including a total of 24 layer, have been identified in this investigation.

From the study of materials and techniques of execution, three large groups were identified: historical polychroming, which includes the original ones, with a common denominator of the use of white lead, red lead, cinnabar, malachite, natural azurite, organic black, and gold. The intermediate layers, have as a fundamental characteristic the use in large measure of artificial azurite, and the last layers show the massive use of synthetic pigments from the $18^{\text {th }}$ and $19^{\text {th }}$ centuries, such as artificial ultramarine blue, emerald green, copper arsenate, and chrome yellow. In the recent interventions, yellow layers, made up of a mixture of oil and resins plus ochres or litharge pigments, simulate a yellow tone analogous to gold and were used as the pictorial layer instead of gold or as the gold base.

The original preparatory layers are the characteristics of panel painting with gesso, phyllosilicates, and agglutinants with protein glues. On these, a stratum of red lead was applied as a base for the first pictorial layer. Other preparations were identified that serve as a reference for the chronological attribution, such as white lead and red lead with linseed oil. This preparation was observed in all the supports, whether wood, plaster, or stone.

The intermediate polychrome layers and the more recent ones were done in oil, and furthermore in subsequent interventions, applications were made in oil and terpenic resins used to fortify and refresh the layers. The study of agglutinants of the deeper strata show that the technique used in the original strata was tempera. These results coincide with the references in the documentary sources. 
TABLE 2. Colour, pigments and agglutinants of the polychrome decoration shown in Figure 18. It corresponds to the honeycomb work or stalactite work (mocárabes) of the façade

\begin{tabular}{llll}
\hline No. layer & Colour & \multicolumn{1}{c}{ Pigments } & \multicolumn{1}{c}{ Agglutinants } \\
\hline 1 & Brown & Phyllosilicates, gypsum & Animal glue \\
2 & White & White lead, quartz and calcite & Animal glue, linseed oil (traces) \\
3 & Red & Red lead & egg tempera, linseed oil \\
\hline
\end{tabular}

\section{ACKNOWLEDGEMENTS}

We thank the technicians of Scientific Instrumentation Center of the University of Granada for their help during analytical work. In particular, we have sincerely appreciated the help of Dr. Parra Crego of the Larco Química y Arte laboratories (Madrid).

\section{REFERENCES}

1. Martín-Ramos, J.D. (2004) Using Xpowder a sofware package for powder X-ray diffraction analysis. D.L. GR-1001/04; ISBN:84-609-1497-6, Spain. http://www. xpowder.com.

2. Down, R.T. (2006) The RRUFF Project: an integrated study of the chemistry, crystallography, Raman and infrared spectroscopy of minerals. Program and Abstracts 19th General Meeting International Mineralogical Association, Kobe, Japan. O03-13. http://rruff.info/.

3. Castro, K.; Pérez-Alonso, M.; Rodríguez-Laso, M.D.; Fernández, L.A.; Madariaga, J.M. (2005) On-line FT-Raman and dispersive Raman spectra database of artist' materials (e-VISART database). Anal. Bioanal. Chem. 382, 248-258. http://dx.doi.org/10.1007/s00216-005-3072-0.

4. Bell, I.M.; Clark, R.J.H.; Gibbs, P.J. (1997) Raman spectroscopic library of natural and synthetic pigments (pre 1850 AD). Spectrochimica Acta Part A 53, 2159-2179. http://dx.doi.org/10.1016/S1386-1425(97)00140-6.

5. Bersani D.; Lottici P.P.; Casoli A.; Cauzzi D. (2008) Pigments and binders in "Madonna col Bambino e S. Giovannino" by Botticelli investigated by micro-Raman and GC/MS. J. Cult. Herit. 9, 97-102. http://dx.doi.org/ 10.1016/j.culher.2007.05.005.

6. Halpine, S. (1992) Amino acid analysis of proteinaceous media from Cosimo Tura's The Annunciation with Saint Francis and Saint Louis of Toulouse. Studies in Conservation $37,22-38$.
7. Gettens, R.J.; FitzHugh, E.W.; Feller, R.L. (1993) Calcium carbonate whites. In: Artists' pigments: A handbook of their history and characteristics. Vol. 2, A. Roy (ed.). D.C. National Gallery of Art Washington, Oxford Univ. Press, 203-226.

8. Eastaugh, N.; Walsh, V.; Chaplin, T.; Siddal, R. (2004) The pigment compendium. Optical microscopy of historical pigments. Elsevier, Amsterdan.

9. Bearn, J.G. (1923) The Chemistry of paints, pigments and varnishes. Ernest Benn Ltd, London.

10. Jaró, M.; Kriston, L. (1987) L'Analyse des piments bruts romains découberts a Baláca. 8th triennial Meeting. Sydney. Australia. Vol. 2. ICOM Committee for Conservation. 763-764.

11. Kühn, H. (1993) Lead-Tin Yellow. In: Artists' pigments: A handbook of their history and characteristics. Vol. 2, A. Roy (ed.). D.C. National Gallery of Art Washington, Oxford Univ. Press, 83-112.

12. FitzHugh, E.W. (1986) Red lead and minium. In: Artists' pigments: A handbook of their history and characteristics. Vol. 1, R.L. Feller (ed.). D.C. National Gallery of Art Washington, Oxford Univ. Press, 109-139.

13. Gettens, R.J.; FitzHugh, E.W. (1993) Azurite and blue verditer. In: Artists' pigments: A handbook of their history and characteristics. Vol. 2, A. Roy (ed.). D.C. National Gallery of Art Washington, Oxford Univ. Press, 23-35.

14. Plester, J. (1993) Ultramarine blue, natural and artificial. In: Artists' pigments: A handbook of their history and characteristics. Vol. 2, A. Roy (ed.). D.C. National Gallery of Art Washington, Oxford Univ. Press, 37-65.

15. Matteini, M.; Moles, A. (2008) La química en la restauración. Los materiales del arte pictórico. ( $2^{\mathrm{a}}$ ed). Nerea, San Sebastián.

16. Fiedler, I.; Bayard, M. (1997) Emerald green and Scheele's green. In: Artists' Pigments: A handbook of their history and characteristics. Vol. 3, E.W. FitzHugh (ed.). D.C. National Gallery of Art Washington, Oxford Univ. Press, 219-272.

17. Chávez González, M.R. (2004) El Alcázar de Sevilla en el siglo XIX. Patronato del Real Alcázar de Sevilla, Sevilla. 